3 Rechsteiner, M. (1987) Annu. Rev. Cell Biol. 3, 1-30

4 Rechsteiner, M., ed. (1988) Ubiquitin, Plenum Press

5 Schlesinger, M. J. and Hershko, A., eds (1988) The Ubiquitin System, Cold Spring Harbor Laboratory

6 Hershko, A. (1988) J. Bioi. Chem. 263, 15237-15240

7 Hershko, A., Heller, H., Eytan, E., Kaklij, G. and Rose, I. A. (1984) Proc. Natl Acad. Sci.USA 81, 7201-7205

8 Chin, D. T., Carlson, N., Kuchl, L. and Rechsteiner, M. (1986) J. Biol. Chem. 261, 3883-3890

9 Brown, J. L. and Roberts, W. K. (1976) J. Biol. Chem. 251, 1009-1014

10 Bachmair, A., Finley, D. and Varshavsky, A. (1986) Science 234, 179-186

11 Varshavsky, A., Bachmair, A., Finley, D., Gonda, D. and Wunning, I. see Ref. 4, pp. 287-324
12 Arfin, S. M. and Bradshaw, R. A. (1988) Biochemistry 27, 7979-7984

13 Hershko, A., Heller, H., Eytan, E. and Reiss, Y. (1986) J. Biol. Chem. 261, 1199211999

14 Rose, 1. A., O'Connell, E. L. and Litwin, S. (1974) J. Biol. Chem. 249, 5163-5168

15 Reiss, Y., Kaim, D. and Hershko, A. (1988) J. Biol. Chem. 263, 2693-2698

16 Gonda, D. K., Bachmair, A., Wünning, I., Tobias, J. W., Lane, W. S. and Varshavsky, A. (1989) J. Biol. Chem. 264, 16700-16712

17 Ferber, S. and Ciechanover, A. (1986) J. Biol. Chem. 261, 3128-3134

18 Ciechanover, A., Wolin, S. L., Steitz, J. A. and Lodish, H. F. (1985) Proc. Natl Acad. Sci. USA 82, 1341-1345

19 Soffer, R. L. (1973) Mol. Cell. Biochem. 2, 3-14

20 Ferber, S. and Ciechanover, A. (1987) Nature $326,808-811$

21 Rogers, S., Wells, R. and Rechsteiner, M.
(1986) Science 234, 179-186

22 Mcllhinney, A. and Hogan, B. L. M. (1974) FEBS Lett. 40, 297-301

23 Ciechanover, A., Finley, D. and Varshavsky, A. (1984) Cell 37, 57-66

24 Hershko, A., Eytan, E., Ciechanover, A and Haas, A. L. (1982) J. Biol. Chem. 257. 13964-13970

25 Bachmair, A. and Varshavsky, A. (1989) Cell 56, 1019-1032

26 Chau, V., Tobias, J. W., Bachmair, A., Marriott, D., Ecker, D. J., Gonda, D. K. and Varshavsky, A. (1989) Science 243, $1576-$ 1583

27 Mayer, A., Siegel, N. R., Schwartz, A. L. and Ciechanover, A. (1989) Science 244, $1480-1483$

28 Pickart, C. M. and Rose, I. A. (1985) J. Biol. Chem. 260, 1573-1581

29 Sherman, F., Stewart, J. W. and Tsunasawa, F. (1985) Bioassays 3, 27-31

30 Rechsteiner, M., Rogers, S. and Rote, K. (1987) Trends Biochem. Sci. 12, 390-394

\title{
Nitric oxide: biosynthesis and biological significance
}

\author{
Michael A. Marletta
}

The recent discovery that mammalian cells can synthesize nitric oxide coincided with the identification of this simple gas as a factor involved in cellular communication. Nitric oxide has now been shown to be derived from L-arginine in macrophages, endothelial cells and possibly other cell types. Its physiological role in macrophages may be as a cytotoxic agent. However, nitric oxide produced by endothelial cells is thought to trigger vascular smooth muscle relaxation through activation of the enzyme guanylate cyclase.

The study of what appeared to be quite diverse physiological reactions led to the discovery of nitric oxide $(\cdot \mathrm{N}=\mathrm{O})$ as a mammalian metabolite that plays a critical role in cellular communication as well as other important functions. The investigation of the apparent synthesis of nitrate $\left(\mathrm{NO}_{3}^{-}\right)$by mammalian cells revealed that, in macrophages, $\cdot \mathrm{N}=\mathrm{O}$ was an intermediate in the production of both $\mathrm{NO}_{3}^{-}$and nitrite $\left(\mathrm{NO}_{2}^{-}\right)$ from L-arginine. In quite unrelated experiments, a factor produced by endothelial cells was shown to be required for the acetylcholine-induced relaxation of vascular smooth muscle. This factor has now been identified as $\cdot \mathrm{N}=\mathrm{O}$, also derived from $\mathrm{L}$-arginine. This review will summarize these initial studies that led to the identification of

M. A. Marletta is at the College of Pharmacy and Department of Biological Chemistry School of Medicine, The University of Michigan, 428 Church Street, Ann Arbor, MI 48109-1065, USA. $\cdot \mathrm{N}=\mathrm{O}$ as a metabolite and examine its biochemical synthesis and possible biological function. Another recent review by Moncada and colleagues ${ }^{1}$ emphasizes the regulation of cell function and communication.

It is rare to find such a reactive molecule as a free intermediate in mammalian biochemistry. The chemistry of $\cdot \mathrm{N}=\mathrm{O}$ has been studied a great deal although not typically under biological conditions. Nitric oxide reacts readily with molecular oxygen in the gas phase and in aqueous solution to yield nitrogen dioxide $\left(\mathrm{NO}_{2}\right)$ which is also reactive and ultimately reacts to form $\mathrm{NO}_{2}^{-}$ and $\mathrm{NO}_{3}^{-}$via the hydrolysis of $\mathrm{N}_{2} \mathrm{O}_{3}$ and $\mathrm{N}_{2} \mathrm{O}_{4}$. The role of $\cdot \mathrm{N}=\mathrm{O}$ as an enzymebound intermediate in the reduction of $\mathrm{NO}_{2}^{-}$by anaerobic denitrifying bacteria has been demonstrated by Hollocher and co-workers over the last several years ${ }^{2}$, however, as will be described below, the mammalian pathway for $\cdot \mathrm{N}=\mathrm{O}$ is quite distinct from the bacterial reductive pathway.

\section{Macrophage synthesis of $\mathrm{NO}_{2}^{-}$and $\mathrm{NO}_{3}^{-}$}

The first metabolic balance studies consistent with mammalian synthesis of $\mathrm{NO}_{3}^{-}$were carried out at the turn of the century (see Ref. 3 and references therein). Renewed interest in $\mathrm{NO}_{3}^{-}$ synthesis in humans stemmed from the potential for the formation of carcinogenic $N$-nitrosamines using this metabolically-derived $\mathrm{NO}_{3}^{-}$as a reactant. The endogenous formation of $N$ nitrosamines has been under investigation for about the last 20 years and the conditions that could lead to the reaction of secondary amines with $\mathrm{NO}_{2}^{-}$ have been well studied ${ }^{3}$. Previously, exposure to $\mathrm{NO}_{3}^{-}$was always presumed to be that from environmental sources.

Tannenbaum and co-workers ${ }^{3}$ first showed that $\mathrm{NO}_{3}^{-}$synthesis was indeed a mammalian process. They found that humans and rats, when maintained on a low $\mathrm{NO}_{3}^{-}$diet $\left(\sim 180 \mu \mathrm{mol} \mathrm{day}{ }^{-1}\right.$ for humans), excreted levels well above the ingested amount. Similar results were obtained with germ-free rats, thus ruling out the participation of gut microflora in the reaction. During the course of the human experiments, one of the subjects coincidentally became ill and showed a large increase in urinary $\mathrm{NO}_{3}^{-}$excretion. Subsequent experiments in rats showed that the urinary $\mathrm{NO}_{3}^{-}$levels could be elevated about tenfold when fever was induced by an intraperitoneal injection of $E$. coli lipopolysaccharide (LPS) ${ }^{3}$. These findings suggested that this elevated synthesis might be related to the immunostimulation known to be brought about by LPS.

The studies above suggested a poten- 
tial origin of $\mathrm{NO}_{3}^{-}$synthesis and, perhaps more importantly, an experimental approach to the problem. Studies carried out with inbred strains of mice which had been characterized with defects in either T cells, B cells or macrophages suggested that after immunostimulation, the macrophage was responsible for this increase in $\mathrm{NO}_{3}^{-}$synthesis ${ }^{4}$. This LPS-induced synthesis in vivo was then reproduced by treatment of murine peritoneal macrophages in culture ${ }^{4}$. LPS-treated macrophages typically synthesized about 150 nanomoles per $10^{6}$ cells per 24 hours ${ }^{4}$. Further in vivo studies showed that strong immunostimulants such as Bacillus Calmette-Guerin increased urinary $\mathrm{NO}_{3}^{-}$excretion in mice up to 50 -fold ${ }^{4}$, suggesting that endogenous lymphokines could also stimulate macrophages to carry out this synthesis. Subsequent experiments showed that a major lymphokine involved in this response was interferon- $\gamma$ $(\text { IFN }-\gamma)^{5}$. The stimulatory effects of LPS and IFN- $\gamma$ were synergistic ${ }^{5}$ and a number of murine macrophage cell lines were found to respond in a similar fashion to LPS and IFN- $\gamma^{6}$.

Further studies with the RAW 264.7 macrophage cell line showed that the chemical precursor to $\mathrm{NO}_{2}^{-}$and $\mathrm{NO}_{3}^{-}$ was exclusively the amino acid L-arginine which was converted to citrulline $^{7}$. Experiments carried out with L-[guanidino- $\left.{ }^{15} \mathrm{~N}_{2}\right]$-arginine unequivocally showed that the nitrogen atoms of both $\mathrm{NO}_{2}^{-}$and $\mathrm{NO}_{3}^{-}$were derived solely from one of the two chemically equivalent ${ }^{15} \mathrm{~N}$-labeled nitrogens ${ }^{7}$. Initially it was assumed that the $\mathrm{NO}_{3}^{-}$resulted from the oxidation of $\mathrm{NO}_{2}^{-}$but experiments suggested that both anions were derived from a common intermediate ${ }^{5}$; experiments with L- $\left[\right.$ guanidino- $\left.{ }^{15} \mathrm{~N}_{2}\right]$-arginine showed that $\cdot \mathrm{N}=\mathrm{O}$ was labeled ${ }^{8,9}$. The formation of $\mathrm{NO}_{2}^{-}$and $\mathrm{NO}_{3}^{-}$was specific for the $\mathrm{L}(S)$ stereochemistry at the $\alpha$-carbon of arginine ${ }^{7}$. Hibbs anc co-workers had been studying the cytostasis in certain tumor target cells induced by co-culture with activated macrophages. They found that this cytostatic-inducing property required L-arginine in the cell culture medium ${ }^{10}$, and they showed, using unlabeled L-arginine, that activated macrophages synthesized $\mathrm{NO}_{2}^{-}$and citrulline from L-arginine ${ }^{11}$.

\section{Endothelium-derived relaxing factor (EDRF)}

In 1980, Furchgott and Zawadzki showed that endothelial cells were required for the acetylcholine-induced relaxation of vascular smooth muscle. A number of substances are now known that lead to the release of endothelium-derived relaxing factor (EDRF), including adenine nucleotides, calcium ionophores and bradykinin. The major pharmacological properties of EDRF are smooth muscle relaxation in a number of different vascular preparations and the inhibition of platelet aggregation ${ }^{12,13}$. Speculation about the structure of EDRF continued until 1986 when Furchgott and Ignarro suggested that it might in fact be $\cdot \mathrm{N}=\mathrm{O}$. Experiments carried out by Moncada and colleagues ${ }^{14}$ showed that EDRF was indeed $\cdot \mathrm{N}=\mathrm{O}$. Using a bioassay consisting of a strip of smooth muscle superfused by effluent from a column containing porcine aortic endothelial cells immobilized on microcarriers, they showed that release of EDRF from bradykinin-stimulated cells led to relaxation in the strip of smooth muscle. A number of indirect experiments showed the structure of EDRF was consistent with the chemical properties of $\cdot \mathrm{N}=\mathrm{O}$. Then, using chemiluminescence detection, they directly observed the formation of $\cdot \mathrm{N}=\mathrm{O}$. This finding has been reproduced now by several laboratories. Moncada and colleagues next showed that the precursor to $\cdot \mathrm{N}=\mathrm{O}$ was L-arginine ${ }^{15}$, suggesting an identical pathway to that characterized in macrophages. There is some evidence that polybasic polypeptides containing $\mathrm{L}$-arginine can serve as substrates for EDRF generation but it is not clear if these alternate substrates serve simply as metabolic precursors to L-arginine. The identification of $\cdot \mathrm{N}=\mathrm{O}$ as EDRF suggests a mechanism of action for the vasodilatory drugs such as amyl nitrite and nitroglycerin. Used since the 19th century, these compounds will produce $\cdot \mathrm{N}=\mathrm{O}$ in the presence of thiols such as glutathione thereby circumventing the generation of $\cdot \mathrm{N}=\mathrm{O}$ from $\mathrm{L}$-arginine.

\section{Biosynthesis of $\cdot \mathbf{N}=\mathbf{O}$ \\ General characteristics}

While the pathway itself appears to be identical in macrophages and endothelial cells, its regulation in the two cell types is quite different. In macrophages no enzymatic activity is observed in either freshly isolated, thioglycolate-elicited peritoneal cells or in any of the macrophage cell lines examined without activation by LPS and/or IFN- $\gamma^{4-6}$. A lag phase that is dependent on the concentration of the activating agent(s) is observed during which time protein synthesis required for the expression of the pathway takes place. After the lag phase that is typically about eight hours, the synthesis of $\mathrm{NO}_{2}^{-}$and $\mathrm{NO}_{3}^{-}$begins and continues linearly for about 48 hours after which time cell death leads to a decreased rate of synthesis ${ }^{6}$. The similarity of freshly isolated cells and cell lines has been demonstrated and we have made use of cell lines extensively, in particular the RAW 264.7 line that is both quantitatively and qualitatively identical to freshly isolated cells ${ }^{6}$. In the cell-free system described below the synthesis of $\cdot \mathrm{N}=\mathrm{O}$, and consequently $\mathrm{NO}_{2}^{-}$and $\mathrm{NO}_{3}^{-}$, continues as long as the substrates are available ${ }^{8}$.

The situation in endothelial cells is very different. Protein synthesis is apparently not required. Stimulation by, for example, bradykinin, leads to an immediate burst in $\cdot \mathrm{N}=\mathrm{O}$ synthesis which decays rapidly ${ }^{14}$. When $1-2 x$ $10^{7}$ cells were stimulated with bradykinin at $10 \mathrm{~min}$ intervals, the amounts produced $(<1 \mathrm{nmol})$ are small relative to those produced in the macrophage but nonetheless significant. The rapid decay is due to reaction with $\mathrm{O}_{2}$, leading to production of $\mathrm{NO}_{2}^{-}$and $\mathrm{NO}_{3}^{-}$, typically in amounts below the limit of detection. When stimulated with bradykinin at 10 minute intervals, $\cdot \mathrm{N}=\mathrm{O}$ was released with each treatment, the amount released (between $70 \mathrm{pmol}$ and approximately $0.7 \mathrm{nmol}$ ) being dependent on the concentration of bradykinin used ${ }^{12.14}$. The calcium ionophore A23187 is the only stimulant that leads to an extended release of $\cdot \mathrm{N}=\mathrm{O}$ (Ref. 15); an immediate increase in $\cdot \mathrm{N}=\mathrm{O}$ decays slowly over the next 30 minutes. This is presumably due to an extended but decreasing rate of synthesis along with a continual decomposition reaction

A recent report is consistent with the generation of $\cdot \mathrm{N}=\mathrm{O}$ in the rat cerebellum after stimulation of $N$-methylD-aspartate receptors ${ }^{16}$. Nitric oxide was not measured directly, but the indirect experiments are all consistent with the chemical properties of $\cdot \mathrm{N}=\mathrm{O}$. The burst of $\cdot \mathrm{N}=\mathrm{O}$ formation is similar to that observed in endothelial cells.

\section{Substrate, products and inhibitors}

When activated macrophages were placed in media that lacked all free amino acids, synthesis of $\mathrm{NO}_{2}^{-}$and $\mathrm{NO}_{3}^{-}$was $25-30 \%$ of that obtained in the normal media. The only amino acid 


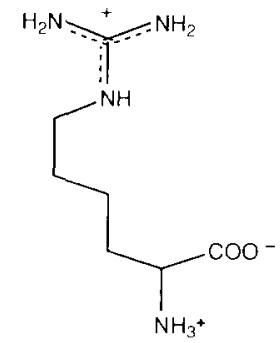

L-homoarginine

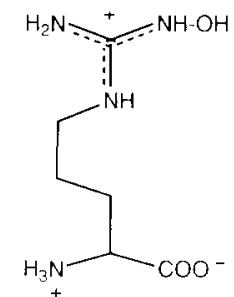

$N^{\mathrm{G}}$-hydroxy-L-arginine

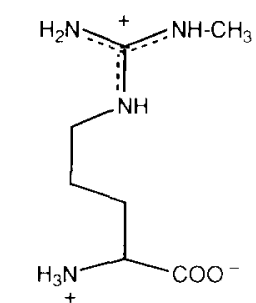

$N^{G}$-monomethylL-arginine

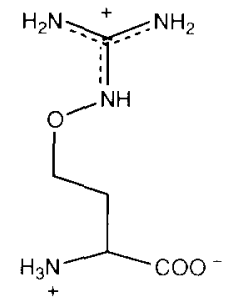

L-canavanine
Fig. 1. Substrates (left) and inhibitors (right) of $\cdot \mathrm{N}=\mathrm{O}, \mathrm{NO}_{2}^{-}$and $\mathrm{NO}_{3}^{-}$formation. See text for details.

that restored the synthesis of $\mathrm{NO}_{2}^{-}$and $\mathrm{NO}_{3}^{-}$was L-arginine. In fact, $\mathrm{L}$-arginine at $2 \mathrm{~mm}$ gave $120 \%$ the value obtained with the amino acid complete media that contains $0.6 \mathrm{~mm}$ L-arginine. No other naturally occurring amino acid was shown to be a substrate ${ }^{5}$. The background synthesis obtained in the amino acid free medium is probably derived from endogenous arginine, and results with varying concentrations of $\left[{ }^{15} \mathrm{~N}\right]$ arginine are consistent with this conclusion ${ }^{7}$. Studies with ${ }^{14} \mathrm{C}$-labeled L-arginine showed that citrulline was the other product of the reaction ${ }^{7}$ and although the stereochemistry at the $\alpha$-carbon was never determined, it has been assumed not to change. No intermediates involving the amino acid backbone were observed. In addition, $\mathrm{NH}_{3}$ and $\mathrm{NH}_{2} \mathrm{OH}$ were not substrates, ruling out the speculation that the pathway involved hydrolysis of L-arginine to citrulline and $\mathrm{NH}_{3}$ followed by the oxidation of $\mathrm{NH}_{3}$ to $\mathrm{NO}_{2}^{-}$and $\mathrm{NO}_{3}^{-}$ (Ref. 11). The enzyme catalysing this hydrolysis reaction, arginine deimidase, has never been reported in mammalian tissues. The reaction seems to be quite specific for L-arginine. Equimolar concentrations of L-homoarginine (Fig. 1) are about $80 \%$ as efficient for $\mathrm{NO}_{2}^{-}$and $\mathrm{NO}_{3}^{-}$synthesis ${ }^{7}$. D-Arginine is not a substrate nor does it inhibit the reaction ${ }^{7,10}$ either in vivo or in a cell-free system, thus ruling out the possibility of the inability of D-arginine to enter the cell. Moncada and colleagues have shown that the $\cdot \mathrm{N}=\mathrm{O}$ pro- duced from endothelial cells is derived from the same guanidino nitrogens of L-arginine ${ }^{15}$. These experiments again utilized L-[guanidino- $\left.{ }^{15} \mathrm{~N}_{2}\right]-$ arginine with bradykinin stimulation.

A limited number of compounds have been studied as potential inhibitors of this reaction. Hibbs and coworkers were the first to show that a monomethylated arginine analogue, $N^{\mathrm{G}}$-monomethyl-L-arginine (Fig. 1) inhibited $\mathrm{NO}_{2}^{-}$formation in macrophages $^{11}$. The inhibition in the cell free activity from macrophages was $50 \%$ at $130 \mu \mathrm{M}$ (Ref. 8). This compound was shown to have a similar inhibitory effect in endothelial cells ${ }^{15}$. In contrast, L-canavanine, a fairly broad inhibitor of arginine-utilizing reactions, inhibits $\mathrm{NO}_{2}^{-}$and $\mathrm{NO}_{3}^{-}$synthesis in macrophages ${ }^{7}$ but has no effect on the reaction in endothelial cell cultures ${ }^{15}$ or homogenates ${ }^{17}$. Thus, although the pathway of $\cdot \mathrm{N}=\mathrm{O}$ formation in the two cell types seems to be identical there may be subtle differences in the enzymes involved. The major difference between the two cell types seems to be in the regulation of the biosynthetic pathway, which may be related to physiological function.

\section{Current status of the enzymology}

Although some progress has been made, the molecular mechanisms of this unusual oxidation of arginine remain largely unknown. The enzyme activity in macrophages and endothelial cells is found in the cytosol ${ }^{8,17}$; activity was recovered exclusively in the $100000 \mathrm{~g}$ supernatant in subcellular fractionation experiments. In addition, reducing equivalents are required in broken cell preparations. NADPH, but not NADH or ascorbic acid, will support the oxidation of arginine to citrulline and $\cdot \mathrm{N}=\mathrm{O}$ with subsequent decomposition of the $\cdot \mathrm{N}=\mathrm{O}$ to $\mathrm{NO}_{2}^{-}$ and $\mathrm{NO}_{3}^{-}$(Ref. 8). Supernatant from non-activated RAW 264.7 cells was completely inactive. The activity in endothelial cell $100000 \mathrm{~g}$ supernatant also required NADPH and was inhibited by $N^{\mathrm{G}}$-monomethyl-Larginine ${ }^{17}$.

All the evidence suggested that the first step of the reaction pathway was the hydroxylation of arginine at one of two equivalent guanidino nitrogens forming $N^{\mathrm{G}}$-hydroxy-L-arginine (Fig. 1). A synthetic version of this compound (Nanjappan, Woodard and Marletta, unpublished), has been shown to be a substrate for the reaction leading to $\mathrm{NO}_{2}^{-}, \mathrm{NO}_{3}^{-}$and citrulline in a cell-free system (Pufahl, Tayeh, Nanjappan, Woodard and Marletta, unpublished). The reaction also required NADPH. $\quad N^{\mathrm{G}}$-Hydroxy-L-homoarginine was also synthesized and found to be a substrate.

A proposed scheme that is consistent with all the evidence obtained to date is shown in Fig. 2 (Ref. 8). The first step illustrates the hydroxylation of arginine yielding $N^{G}$-hydroxy-L-arginine. Although steps 2-5 are speculative, they do provide a chemically reasonable pathway to give the final products of the reaction, citrulline, $\mathrm{NO}_{2}^{-}$and $\mathrm{NO}_{3}^{-}$. Step 2 simply shows a twoelectron oxidation of the hydroxylamine moiety, a common reaction for this relatively unstable functional group, producing $N^{\mathrm{G}}$-oxo-L-arginine. The electron acceptor in this reaction is presently unknown. This product could also be formed by a second hydroxylation upon $N^{\mathrm{G}}$-hydroxy-L-arginine followed by a dehydration. This would explain the need for additional NADPH when $N^{\mathrm{G}}$-hydroxy-L-arginine is used as a substrate. The attractive feature of the third step is that, by simple loss of a hydrogen atom, the amino acid radical generated would be expected to be very unstable and should fragment as indicated in step 4 to yield $\cdot \mathrm{N}=\mathrm{O}$ and an amino acid carbodiimide. This compound, $N$ - [ (2amino)-valeryl]-carbodiimide, would be expected to react with $\mathrm{H}_{2} \mathrm{O}$ in a manner typical of carbodiimides to yield, in this particular case, citrulline.

Early efforts directed toward the purification of the enzyme(s) involved in this reaction pathway were hampered by the apparent instability of the activity. A series of experiments showed that this loss of activity was not due to enzyme instability, but to the loss of a low molecular weight cofactor, recently shown to be tetrahydrobiopterin $^{18}$. Arginine loss and product formation are dependent on tetrahydrobiopterin. The other three mammalian tetrahydrobiopterin-requiring hydroxylases (phenylalanine-, tyrosine- and tryptophan-hydroxylase) all carry out reactions at aromatic carbons and so these results suggest a novel hydroxylation for tetra-hydrobiopterin at a guanidino nitrogen.

\section{Biological function of nitric oxide generation}

The proposals regarding the biological role for $\cdot \mathrm{N}=\mathrm{O}$ have mainly centered around the enzyme guanylate cyclase. This enzyme catalyses the conversion 
of GTP to cyclic GMP (cGMP). It had been known for some time that $\cdot \mathrm{N}=\mathrm{O}$ was capable of activating guanylate cyclase leading to a substantial increase in cGMP levels ${ }^{19}$. Other compounds that activate guanylate cyclase include $\mathrm{NaN}_{3}, \mathrm{NH}_{2} \mathrm{OH}, \mathrm{NaNO}_{2}$, nitroglycerin and sodium nitroprusside. Under biological conditions all these agents are capable of generating $\cdot \mathrm{N}=\mathrm{O}$. The enzyme is ubiquitous and exists in both soluble and particulate (membrane bound) forms. Both forms are generally found in the same cell, although the amounts and subcellular localization vary from cell to cell and are influenced by the particular physiological state of the cell. The soluble enzyme has been purified to homogeneity from a number of sources and, consequently, has received more attention than the particulate form. The purified soluble enzyme will bind a heme prosthetic group and the reaction of $\cdot \mathrm{N}=\mathrm{O}$ with iron proteins, particularly hemoproteins, is well known ${ }^{21}$. Evidence suggests that binding of $\cdot \mathrm{N}=\mathrm{O}$ to the heme plays a direct role in the activation of the enzyme. The key experiments supporting the $\cdot \mathrm{N}=\mathrm{O}$-heme interaction model have come from a number of laboratories and show that some purification procedures can lead to the loss of the prosthetic heme with resulting loss in the ability to be activated by $\cdot \mathrm{N}=\mathrm{O}$ and related agents. However, reconstitution of the hemedepleted enzyme with hematin and reducing agents, typically thiols, leads to enzyme that can once ag,ain be stimulated by $\cdot \mathrm{N}=\mathrm{O}$ generating compounds ${ }^{19}$. The amount of activation is dependent on the source of the enzyme and ranges from 10 - to 50 -fold. It is also clear that activation of guanylate cyclase involves thiols on the enzyme and the evidence taken together suggests oxidation/reduction processes that are linked to the basal and activated activity of the enzyme. Guanylate cyclase shows high-affinity binding for heme ${ }^{21}$, and studies concerning the physiological importance of this are continuing.

The role of cGMP as a second messenger is not as well developed as that for another cyclic nucleotide, cAMP. However, over the last 5-10 years cGMP has assumed a more prominent role as second messenger, in particular, increases in cGMP have been associated with smooth muscle relaxation. Alterations in $\mathrm{Ca}^{2+}$ levels induced by cGMP ultimately control smooth muscle tension. Several laboratories
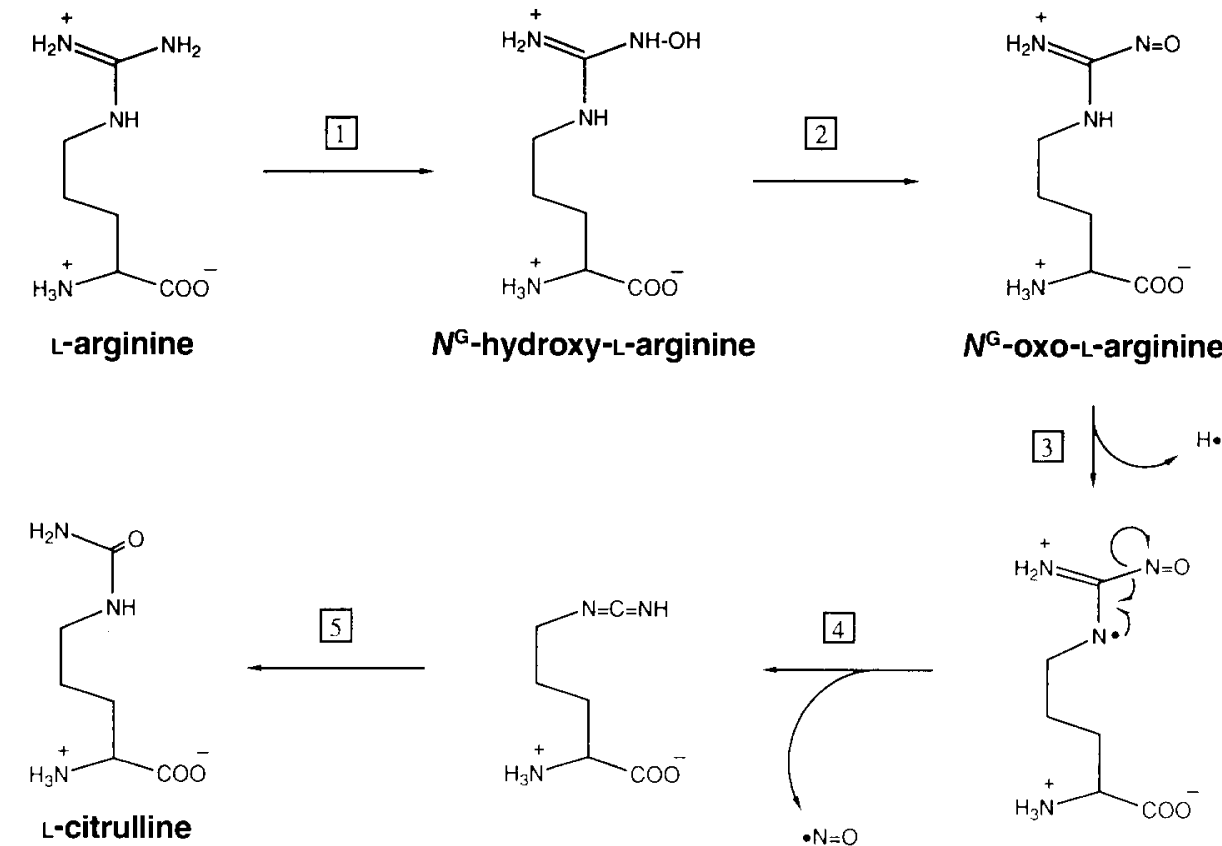

Fig. 2. Reaction scheme (steps 1-5) for the conversion of L-arginine to $-\mathrm{N}=\mathrm{O}, \mathrm{NO}_{2}^{-}, \mathrm{NO}_{3}^{-}$and citrulline.

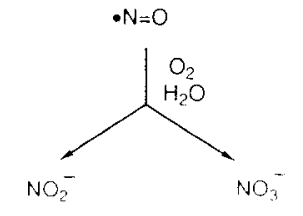

$N^{G}$-oxo-L-arginine

showed that the nitrovasodilators, such as nitroglycerin, produce an increase in cGMP levels in smooth muscle tissue and, as mentioned above, these nitrovasodilators can activate the enzyme guanylate cyclase through the generation of $\cdot \mathrm{N}=\mathrm{O}$. Thus, nitrovasodilators might simply circumvent the generation of $\cdot \mathrm{N}=\mathrm{O}$ from arginine and produce $\cdot \mathrm{N}=\mathrm{O}$ directly. Taken together, these findings suggest that at least one physiological role of the arginine pathway is to activate guanylate cyclase leading to an increase in the second messenger cGMP. Other recent results support this proposed role including those of Garthwaite and colleagues ${ }^{16}$ who showed that glutamate induced the release of a diffusible messenger that had chemical properties very similar to $\cdot \mathrm{N}=\mathrm{O}$. This appears to be another example of intercellular communication where the intracellular signal is cGMP whose level is increased via the activation by $\cdot \mathrm{N}=\mathrm{O}$. It has long been known that in the central nervous system, and especially in the cerebellum, the excitatory neurotransmitter glutamate can elicit large increases in cGMP levels.

What, then, is the role of $\cdot \mathrm{N}=\mathrm{O}$ production in the macrophage? There are two major possibilities. The killing and cytostasis-inducing functions of activated macrophages might suggest that, through its chemical properties, $\cdot \mathrm{N}=\mathrm{O}$ is acting as a cytotoxic agent. Hibbs and colleagues have reported that L-arginine is required for activated macrophages to induce cytostasis in target tumor cell lines ${ }^{10}$. Furthermore, they have recently reported ${ }^{9}$ that the same pattern of metabolic inhibition induced by macrophages in the tumor cell line can be reproduced directly by $\cdot \mathrm{N}=\mathrm{O}$. On the other hand, it is known that cyclic nucleotides are involved in the regulation of several macrophage functions including phagocytosis, motility, response to lymphokines and DNA synthesis and it has been reported that macrophages treated with $\cdot \mathrm{N}=\mathrm{O}$ generating agents show a large increase in cGMP levels ${ }^{22}$. This would suggest that macrophage killing/cytostatic properties might be cGMP dependent and that the $\cdot \mathrm{N}=\mathrm{O}$ synthesized is used to elevate intracellular cGMP levels.

The involvement of $\cdot \mathrm{N}=\mathrm{O}$ as a key metabolite in the activation of the enzyme guanylate cyclase represents a novel control mechanism. The biochemistry of the pathway of $\cdot \mathrm{N}=\mathrm{O}$ production including the oxidation of $\mathrm{L}$-arginine at the guanidino nitrogen will no doubt involve some novel enzymology that has already begun to unfold. The understanding of this enzymology and regulation of this pathway will ultimately lead to agents specifically designed for the rational control of $\cdot \mathrm{N}=\mathrm{O}$ formation. The pharmacological potential for these new agents is promising. 


\section{Acknowledgements}

The author is very grateful to Mahmoud A. Tayeh, Joan M. Hevel and Robert A. Pufahl for their critical comments on the manuscript. In addition, work in the author's laboratory has been supported by USPHS grants CA26731 and CA50414, the College of Pharmacy, and the Upjohn Research Fund.

\author{
References \\ 1 Moncada, M., Palmer, R. M. J. and Higgs. \\ E. A. (1989) Biochem. Pharmacol. 38, \\ 1709-1715 \\ $2 \mathrm{Kim}, \mathrm{C}-\mathrm{H}$. and Hollocher, T. C. (1983) \\ J. Biol. Chem. 258, 4861-4863 \\ 3 Marletta, M. A. (1988) Chem. Res. Toxicol. \\ $1,249-257$
}

4 Stuehr, D. J. and Marletta, M. A. (1985) Proc. Natl Acad. Sci. USA 82, 7738-7742

5 Stuehr, D. J. and Marletta, M. A. (1987) J. Immunol. 139.518-525

6 Stuehr, D. J. and Marletta, M. A. (1987) Cancer Res. 47.559(-5594

7 lyengar, R., Stuehr, D. J. and Marletta, M. A. (1987) Proc. Natl Acad. Sci. USA 84, 6369-6373

8 Marletta, M. A., Yoon, P. S., Iyengar, R. Leaf, C. D. and Wishnok, J. S. (1988) Biochemistry 27, 8706-8711

9 Hibbs, J. B. Jr, Taintor, R. R., Vavrin, Z. and Rachlin, E. M. (1988) Biochem. Biophys. Res. Commun. 157, 87-94

10) Hibbs, J. B. Jr, Vavrin, Z and Taintor, R. R (1987) J. Immunol. $138,550-565$

11 Hibbs, J. B. Jr, Taintor, R. R. and Vavrin, Z (1987) Science 235, 473-476

12 Moncada, S., Palmer, R. M. J. and Higgs, E. A. (1988) Hypertension 12, 365-372
13 Ignarro, L. J. (1989) FASEB J. 3, 31-36

14 Palmer, R. M. J., Ferrige, A. G. and Moncada, S. (1987) Nature 327, 524-526

15 Palmer, R. M. J., Ashton, D. S. and Moncada, S. (1988) Nature 333, 664-666

16 Garthwaite, J., Charles, S. L. and ChessWilliams, R. (1988) Nature 336, 385-388

17 Palmer. R. M. J. and Moncada, S. (1989) Biochem. Biophys. Res. Commun. 158, 348-352

18 Tayeh, M. A. and Marletta, M. A. (1989) J. Biol. Chem. 264, 19654-19658

19 Waldman, S. A. and Murad, F. (1987) Pharmacol. Rev. 39, 163-196

20 Cassloy, R. and Gibson, Q. H. (1975) J. Mol. Biol. 91, 301-313

21 Ignarro, L. J., Adams, J. B., Horwitz, P. M and Wood, K. S. (1986) J. Biol. Chem. 261. 4997-5002

22 Bromberg, Y. and Pick, E. (1980) Cell. Immunol. 52,73-83

\section{Haem as a multifunctional regulator}

\section{G. Padmanaban, V.Venkateswar and P. N. Rangarajan}

Haem has long been known as the prosthetic group of haemoproteins such as haemoglobin, catalase and the cytochromes. Its biosynthesis is regulated by feedback mechanisms that ensure its adequate production but prevent its overaccumulation, which is highly deleterious as diseases such as porphyrias attest. However, recent years have seen rapid strides in our understanding of how haem (or more accurately haemin, its oxidized form) itself acts as an intracellular regulator of a v. riety of other metabolic pathways for systems that utilize oxygen.

\section{Haem dynamics in the cell}

The haem biosynthetic pathway has been demonstrated in a wide variety of living systems. However, most information on haem dynamics has been obtained with liver cells. It is estimated that $1 \mathrm{ml}$ of marrow erythroblasts can make $6100 \mathrm{nmol} \delta$-aminolevulinate (ALA) $h^{-1}$. (ALA is the first committed precursor of the haem biosynthetic pathway, see Fig. 1.) In liver, ALA is made at a rate of $20-25 \mathrm{nmol}(\mathrm{g} \text { liver })^{-1}$ $h^{-1}$, about $15 \%$ of that of whole bone marrow. In liver ALA is quantitatively converted to haem. The total haem content of liver is estimated to be 2.6 nmol g ${ }^{-1}$ and nearly $65 \%$ of it is used to replenish cytochrome P-450 haem. The 'free and exchangeable' haem pool is thought to be in the range of $10-100$ nM. Fluctuations beyond this range bring about a rapid alteration in the

G. Padmanaban, V. Venkateswar and P. N. Rangarajan are at the Department of Biochemistry and Centre for Genetic Engineering, Indian Institute of Science, Bangalore 560012, India. levels of haem biosynthetic and degradative enzymes ${ }^{1}$.

Haem is synthesized in the mitochondrion and is then distributed to the different haemoproteins located in mitochondria, microsomes, peroxisomes and cytosol. The mechanism of intracellular transport of haem is not very clear. There is some evidence supporting the concept of cytoplasmic haem carriers transporting haem from mitochondria to other locations. Ultrastructural studies have revealed the presence of rough endoplasmic reticulum-mitochondrion (RERM) complexes in the liver cell, and it has been suggested that these complexes would facilitate the integration of haem made in mitochondria with the apocytochrome synthesized on the rough endoplasmic reticulum ${ }^{2}$. Haem is also implicated in transcriptional regulation (see below), and so transport into the nucleus to form a regulatory pool is likely.

Although the bulk of the haem of the liver cell is synthesized in situ, some also reaches the liver as haptoglobinhaemoglobin and haem-haemopexin complexes, arising out of intravascular hemolysis of senescent red cells. Uptake by the liver is mediated by specific receptors. There is evidence that haem from haem-haemopexin reaches several target sites including the liver nucleus ${ }^{3}$. It is not clear whether the newly biosynthesized haem mixes with the haem derived from red cells or whether separate pools are maintained. However, it appears that both should be contributing to the regulatory pool, since haemregulated proteins are responsive to haem levels generated in the mitochondrion as well as to exogenous haem.

\section{Haem regulates its own biosynthesis}

The two crucial enzymes involved in regulating the levels of intracellular haem in liver are ALA synthetase (ALAS) and haem oxygenase ${ }^{1}$. ALAS is induced by a wide variety of chemicals and suppressed by the administration of haem. There is good evidence that haem negatively regulates the synthesis of $\mathrm{ALAS}^{4}$. With the use of cloned cDNA, it has been shown in rat liver that haemin (the oxidized form of haem), actinomycin D and $\alpha$-amanatin bring about a rapid decrease in the intracellular levels of ALAS mRNA. pre-induced by 2-allylisopropylacetamide. Since there is no change in the half-life of ALAS mRNA under these conditions, haemin most likely represses the transcription of the gene ${ }^{5}$. Earlier, this laboratory had proposed a positive regulatory model, where ALAS induction could be positively modulated by apo-cytochrome P-450, the effect ceasing with the formation of the holoprotein ${ }^{6}$. Haem 